\title{
Recommendations for the design, calculation, construction and quality control of stone columns under buildings and sensitive structures
}

\footnotetext{
Forward

This report is a new and revised version of the recommendations published in the RFG No. 111 in 2005. It takes into account both the experimental results and observations of the French Union Syndicale Géotechnique (USG) in the interest of better understanding soil-structure interactions. This version also includes chapters on design based on laboratory and cone penetration tests (CPT). It presents the guidelines to be followed by all building contractors in France (according to Article R111-40 of the French Building and Residential Construction Rules) and oversight entities dealing with the design, calculation, installation and quality control of stone columns and their interaction with buildings and settlement-sensitive structures.

The following participated in drafting this document:

P. Aguado (Apave)

P. Berthelot (Bureau Veritas)

L. Carpinteiro (Socotec)

F. Durand (Fugro Geotechnique)

M. Glandy (Soletanche Bachy Pieux)

P. Liausu (Menard)

B. Pezot (Menard)

C. Poilpre (consultant)

S. Lambert (Keller Fondations Speciales)

J.-P. Volcke (Franki Fondation)

G. Billoet (Keller Fondations Spéciales) and J.R. Gauthey (Spie Fondations) also participated in discussions.

This document has been approved by the Union Syndicale Géotechnique (USG, the French geotechnical union association) and the Comité Français de Mécanique des Sols (CFMS, the French society for soil mechanics, ISSMGE member society).
} 


\section{Introduction}

(1) The columns referred to in these guidelines are vertical piles made of cohesionless granular materials that are driven into the soil and then compacted by repetitive action.

Comment 1: These columns do not contain any particular type of binder at any level. In this document, the term "stone column" is limited to the definition above.

(2) The columns can be constructed in regular or variable grids in rows or groups, or even in isolation.

(3) Their design takes into account the type of structure to be built, the kind of load, tolerances, and requirements regarding absolute and differential settlement, as well as the nature and characteristics of the soil to be treated.

(4) The purpose of stone columns is to give the soil under the structure to be built new general and/ or local characteristics so that the structure's various infrastructure elements (isolated or strip footing, raft foundations, concrete slabs, embankments, etc.) will demonstrate predictable and justifiable behavior consistent with the regulations and tolerances that apply to the structure of the building and its intended use.

(5) Treating soil with stone columns involves a combination of the following actions, of which one or more may be intended:

- Improving bearing capacity.

a Reducing settlement. ristics.

Improving uniformity of geotechnical characte-

- Increasing the consolidation rate by creating drainage elements.

Increasing equivalent ground mass characteristics (horizontal shear strength, angle of internal friction and deformation parameters).

(6) A stone column is a soil improvement measure. It is neither a foundation element, nor a deep foundation element.

(7) The foundation of a structure built on soil treated by stone columns is always superficial (isolated or strip footing, raft foundations, concrete slabs, etc.). It can also be part of the "foundation" of an embankment.

(8) The objective is to control the behavior of these structures, and in particular to reduce the settlement.

Comment 1: Depending on the existing grid density and geotechnical conditions, this coefficient is usually between 1.5 and 4 under distributed loads.

(9) The need for soil treatment should be analyzed by the project's geotechnical engineer, who should provide and approve the calculation hypotheses.

Comment 2: A reminder: the stone column geotechnical study should examine not only the soil to be treated, but any soil that could potentially settle under the treated layer.

Comment 3: The contractor must involve the geotechnical engineer in the design and the execution of the project in compliance with standard NF P 94-500 concerning geotechnical procedures in France.

\section{Fields of application}

2.1.

\section{By type of structure}

(1) The most common uses of stone column treatment involve structures with concrete slabs or raft foundations with surface loads sensitive to settlement:

- Hangars and warehouses.

- Industrial and commercial buildings.

- Silos and tanks of all kinds.

- Watertight hydraulic structures (tanks, sewage treatment plants, etc.)

(2) By extension, they can be used under other types of structures, too, as long as the residual deformations of the treated soil and underlying layers are consistent with the structure in question and with associated technical measures:

- On-shore civil engineering works (roads, embankments, bridges, retaining walls), and maritime structures (seabed, lake and riverbed reinforcement).

Under shallow building foundations.

(3) They can also be used for stable heterogeneous embankments where systematic treatment with an appropriate and regular grid can help improve and/or homogenize the soil characteristics to make it suitable for surface construction.

\section{2}

\section{Use in seismic zones}

(1) It is also possible to use stone columns in seismic zones where they may reduce the risk of soil liquefaction and increase shear resistance.

(2) Refer to the guidelines entitled "Procédés d'amélioration et de renforcement de sols sous sollicitations sismiques" published by the French Association of Earthquake Engineering (AFPS).

\section{3}

\section{Limitations of use}

(1) The lateral earth pressure exerted by the surrounding soil is a determining factor in column construction, behavior and capacity.

(2) Therefore:

Stone columns must not be used in soil that exhibits a potential risk of a loss in volume and/or mechanical soil characteristics, especially waste dumps and peat deposits. More generally, stone columns should not be used in soils with a loss on ignition of more than $5 \%$ as specified by standard XP 94-047.

Comment 1: There is also standard NF P 94-055 which specifies a chemical method for determining the organic material weight content of a soil.

- Unless particular measures have been provided for, such as preloading or consolidation, or a specific compatibility study, treatment with stone columns in highly compressible soils (silt, mud and soft clay) with 
a thickness greater than $50 \mathrm{~cm}$ and weak characteristics $\left(\mathrm{C}_{\mathrm{u}}<20 \mathrm{kPa}\right.$ or $\left.\mathrm{q}_{\mathrm{c}}<300 \mathrm{kPa}\right)$ is not possible.

- In any case, essential design verifications must be carried out to calculate potential stone column failure and deformation as described in Chapter 5 of this document. Specific stresses related to the site must also be taken into account.

\section{3}

\section{Procedure}

\section{1.}

\section{Methods and materials}

(1) The two following methods meet the definition given in the forward (see glossary for a detailed description):

- Vibro-compaction.

- Vibro-stone columns:

- vibro-displacement by a "dry" method where compressed air jetting is used, or

- vibro-replacement by a "wet" method where water jetting is used.

Comment 1: Any other method requires its own technical specifications.

(2) Which device, wet or dry method, characteristics and the implementation method to use depends largely on the nature and the level of soil saturation, the desired objectives, and the characteristics of the gravel fill materials. It is up to the contracting company to decide on the basis of its expertise and experience which process is best adapted to each situation.

\section{2}

\section{Pre-drilling}

(1) Soil displacement through compacted layers or obstacles can be facilitated by pre-drilling, with or without earth excavation.

(2) Excavated or altered volumes should be filled and compacted with the column material.

\section{3.}

\section{Gravel backfill}

(1) The gravel backfill must be of high quality, and its particle size must be as homogeneous as possible.

(2) In most cases natural, pea gravel or crushed stone gravel is used.

Comment 1: Except in the case of specific documentation showing an absence of short and long-term problems (expansion, pollution, physical-chemical reactions, etc.), recycled materials may not be used. are:

(3) The minimum characteristics for gravel backfill

Los Angeles test loss $<35 \%$.

Micro De-val test loss $<30 \%$.

- Combined Los Angeles + Micro D-val test loss $<60 \%$.
Comment 1: Los Angeles test, standard DIN EN 1097-2; Micro De-val test, standard NF EN 1097-1.

(4) The particle size test depends mainly on the backfill material. Bottom-feed vibrators are more sensitive and an unsuitable particle size can plug the pipe.

(5) The following indicative values can be used as a reference:

- Bottom-feed vibrators with a material transfer pipe on the side: the most commonly used particle size is $8 / 40$.

Other methods: the most commonly-used particle size is $20 / 75$.

(6) The standard for particle homogeneity: less than $5 \%$ particles smaller than $80 \mu \mathrm{m}$.

\section{4}

\section{Construction provisions}

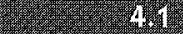

\section{Diameter of stone columns}

(1) The diameter of the stone columns depends on: the site,

the device used and its suitability to the soil at ristics,

the layers of soil penetrated and their characte-

a the total amount of energy used (power output, vertical force and running time).

(2) The diameter of the column may vary over its length, depending on the resistance of the different layers penetrated.

Comment 1: The diameter of most dry method columns is between 50 and $80 \mathrm{~cm}$.

(3) All things equal, the diameter of wet method columns is usually greater than dry method columns due to the soil extraction caused by water jetting.

\section{2}

\section{Interface between the treated soil and the building structure}

(1) If the foundation element does not have enough inertia to distribute load bearing in a homogeneous way on the initial column grid, it is necessary to add a load transfer platform between the foundation elements and the treated soil. The purpose of this plat form is to improve the load bearing distribution.

(2) If the stone columns are being used for their draining properties, a drainage layer (with outlet) should be added at the top of the columns.

Comment 1: In practice, isolated and strip footings and raft foundations do not require a load transfer platform, as opposed to concrete slabs (reinforced or not) which do.

(3) With few exceptions, in general, soil treatment with stone columns does not in and of itself improve the behavior of surface soil between columns where there is no increase in the values for either the EV2 modulus or the Westergaard coefficient. 


\section{Installation of footings and raft foundations}

(1) Footings and raft foundations must be constructed in the same way as on untreated soil. They can be cast directly into the trench or into a formwork.

(2) When the footing base is less than $50 \mathrm{~cm}$ below the work platform level, the head of the column must be re-compacted to ensure the characteristics specified in the calculations.

Comment 1: This re-compacting can be done in conjunction with platform re-compacting.

\section{4.}

\section{Installation of a load transfer platform}

(1) The minimum thickness for a gravel load transfer platform to distribute the load is $40 \mathrm{~cm}$.

(2) In the case of concrete slabs, the top layer of gravel should at least have the characteristics of subgrade as defined by DTU 13.3 and Guide GTR92.

Comment 1: For the purposes of this document, the following should be noted for the subgrade layer:

Class F materials are not permitted (according to standard NF P 11-300).

The minimum thickness is $25 \mathrm{~cm}$. $50 \mathrm{MPa}$.

The modulus of elasticity $E V_{2}$ is greater than

(3) It is up to the soil treatment designer to define the thickness and the minimum characteristics of the platform according to the nature of the treated soil.

Comment 1: Bear in mind that the criteria applied to gravel layer calculations are its punching resistance (if necessary), its thickness and the modulus of elasticity.

(4) The concrete slab designer must verify that the load transfer platform's thickness and characteristics are sufficient to resist the pressure exerted by the concrete slab, including the punching resistance, and that the values remain above the minimum concrete slab requirements (standard NF P 11-213 ref. DTU 13.3 on concrete slabs).

(5) The load transfer platform can be partially or entirely installed before the stone columns and therefore can be used as a work platform.

(6) However, any re-grading, final compacting, and re-treatment of subgrade, as well as any gravel additions to increase thickness should be performed after the installation of the stone columns so that the characteristics in compliance with the project remain consistent.

\section{Configuration of stone columns}

\section{1.}

\section{Structures with uniform distributed loads}

(1) In the case of structures with uniform distributed loads, the columns are laid out in a regular grid, usually square or triangular.

(2) The grid spacing depends on the geotechnical characteristics and applied loads.

Comment 1: Under certain geotechnical and/or load conditions, part of the structure may not be located on treated ground as long as the absolute and differential settlements between areas treated or loaded differently remain consistent with the structure and its usage.

Comment 2: Except in special cases, it is not necessary to extend the column layout beyond the concerned structure.

\section{(16)}

\section{Isolated and strip footing}

(1) The footing dimensions will depend on both the allowable stress and allowable settlement after soil treatment.

(2) The stone column grid spacing is based on the least favorable criterion.

Comment 1: For the same structure, it is entirely possible that some footings may be placed on improved soil, while others with lighter loads may be placed on untreated ground. This situation is allowed in conditions where the uniformity of settlement can be ensured for footings subject to different load levels (e.g. secondary frame structures that support siding for industrial hangars or warehouses).

(3) For individual columns or a single row of columns, in the absence of appropriate verification, the edge of the footing in relation to the theoretical position of the bare outer part of the columns must be at least equal to the installation tolerance specified in $\S 4.9$.

Comment 1: Verification involves making sure that even if the column is not fully under the footing (possibly before installation and mandatorily after verification if there is any column deviation), that the column's deformation and maximum stress results remain allowable.

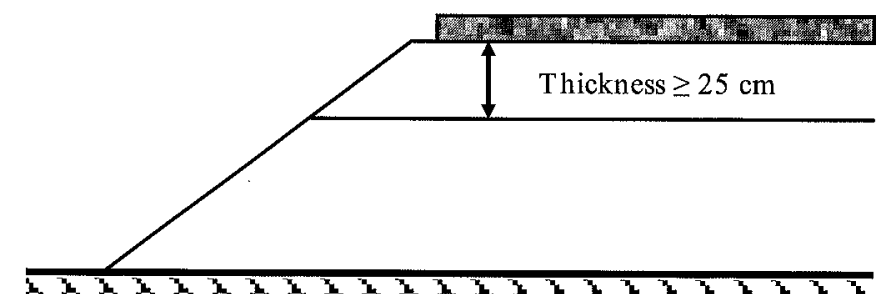

CONCRETE SLAB

TOP LAYER

DISTRIBUTION LAXER

LOAD TRANSFER PLAT FORM 


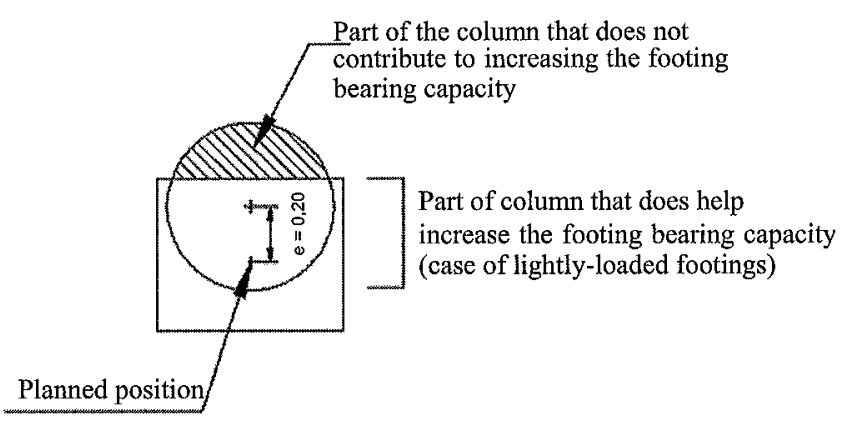

$\mathrm{e}=$ position tolerance (usually $20 \mathrm{~cm}$ )

16.2. Case of columns lying outside of footings.

(4) For columns that are not aligned, it is recommended to adopt the same configuration (footing edge equals at least the installation tolerance). Otherwise, the column settlement and stress must be verified if the columns do not conform to the theoretical layout.

Comment 1: Appendix I includes some standard configurations.

Comment 2: Under strip footings, placing columns in alternate rows limits the incidence of column deviation.

\section{6}

\section{Maximum reference grids}

(1) For soil to be considered treated by stone columns, and whatever the intended objective, the maximum reference grid should be $9 \mathrm{~m}^{2}$ and the substitution rate should be greater than $3 \%$.

(2) For strip footings with a single row of columns and no load transfer platform, the maximum grid spacing without specific justification is $2.5 \mathrm{~m}$.

\section{7}

\section{Minimum reference grids}

(1) The minimum reference grid should be $2.25 \mathrm{~m}^{2}$.

(2) For strip footings and groups of two to five columns, the spacing between the columns axes cannot be less than 1.5 times the diameter of the stone column, or $1.20 \mathrm{~m}$.

Comment 1: A high substitution rate can lead to a risk of raising the platform.

Comment 2: To address specific problems (if part of structure is too small, for example), it is possible to reduce the spacing in (1) and (2) by conducting a feasibility study.

Comment 3: For columns executed with the wet method, a process rarely used for earthen sites due to the soil extraction required, it is possible to use larger diameter stone columns (1.00 to $1.20 \mathrm{~m}$ ) more closely spaced than those installed using the dry method.

\section{8.}

\section{Stone columns under an embankment supporting a foundation}

(1) It is possible to treat all types of soil in the scope of application with stone columns, and then build a substitute or raised embankment on the improved soil using fine, quality-controlled materials and demonstrating the utmost care during installation and strict attention to compaction, for example according to the 1980 recommendations by COPREC LCPC.

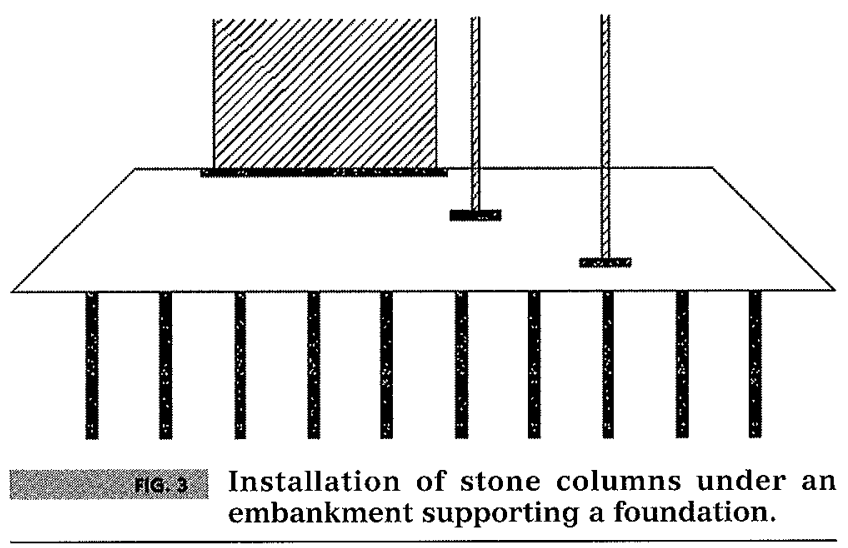

(2) The configuration of the columns takes into account the superposition of stresses generated by the embankment itself and also the various structural elements built into the fill thickness. This configuration requires justification in particular if the height of the embankment is less than half of the reference grid measurement.

\section{$4 \cdot 2$}

\section{Tolerances}

\section{(2) 19.96 \\ Columns in grid networks}

(1) Due to their own characteristics, stone columns can provide new characteristics to soil that are equivalent to soil's basic lattice structure located at its center.

(2) In this case, the concept of column installation deviation does not apply, though it is applicable for localized foundation elements.

\section{2.}

\section{Columns under footings}

(1) The isolated and strip footings installed on treated soil must be considered foundation elements.

(2) The tolerance for stone columns is therefore $\pm 20 \mathrm{~cm}$.

Comment 1: This value can be difficult to assess due to the irregular shape of the columns when they are vibrated.

(3) Above this value, the company must prove that the footing behavior is compatible with the building structure. If there is a gravel layer under the footings, its characteristics are taken into account. 
Comment 1: The constructions built on the columns are designed to remain unchanged as long as installation is completed within the tolerances.

(4) The choice of whether to opt for lower tolerances is left up to the company, but it must ensure strict compliance and the tolerance may not be the same in both directions.

\subsection{0.}

\section{Reduction factor for the volumes of material used}

(1) There is a difference between the theoretical volumes of the columns designed, and the actual volume of the material supplied and thus used onsite. This difference is due to losses during installation (including variations from expected dimensions resulting from lateral pressure) and from compaction of the material in the column.

(2) Usually the following ratios of the real volume to the theoretical volume are accepted:

- Top feed vibrated columns using the wet method: 1.3 to 1.5 .

- Bottom feed columns using the dry method: 1.2.

\section{5 \\ Design}

\section{1}

\section{Prerequisite information needed for calculations}

(1) The behavior of soil reinforced with stone columns cannot be analyzed without extensive knowledge of:

- The nature and characteristics of the soil to be treated and the ground underneath it: soil boring tests, results of onsite, mechanical or laboratory tests, etc.

- The nature, characteristics and construction methods for the actual building foundation itself.

- Regular and unusual stress levels.

- The nature and behavior of the structure to be built.

(2) The calculation rules specified in this document do not take into account any soil improvement between columns.

Comment 1: Installing columns can improve the characteristics of some types of soil. It is possible to take the "improved" characteristics into account as long as appropriate tests are conducted to make sure they can be attained.

\section{5.}

\section{Criteria for determining column size}

(1) Determining the size of stone columns is inextricably linked to the characteristics of the soil to be treated and the implementation process.

(2) In general, the justifications that need to be provided in the calculations are based on these two criteria:
- The overall allowable bearing capacity for the improved soil after treatment and justification of the different types of foundations regarding failure, and

- The absolute settlement of the various structural aspects for each construction and justification of the differential settlement for the structure, or between the structure and the concrete slab according to the allowable tolerances for each construction and any relevant regulations in effect.

(3) When there are other objectives set, the following additional information must also be provided:

- In the case of soil liquefaction, it must be shown that the columns will minimize this risk.

- If the columns are intended to act as vertical drains to accelerate consolidation, the consolidation time is calculated.

- In the case of slope stabilization, the calculation compares the factor of safety to the circular failure rate.

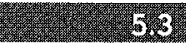

\section{Hypotheses}

(1) The building construction constraints (maximum bearing capacity and allowable deformation) must be specified in the documents specific to the project.

(2) The soil behavior hypotheses are the geotechnical characteristics identified from soil tests: stratigraphy, soil composition, hydrology, rheological and mechanical properties (Young's modulus, Poisson's ratio, lateral earth pressure, compression index $\mathrm{C}_{\mathrm{c}}$, void ratio, etc.) for all soil layers.

Comment 1: When the data result from correlations, it is best to obtain written consent from the geotechnical engineer attesting to the validity of the hypotheses under consideration.

(3) The hypotheses concerning the stone columns, especially in terms of their modulus of deformation, diameter and length depend in large part on the material used and its performance.

(4) Common values for non-geometrical parameters used in the calculations for the backfill materials described in $\S 3.3$ and correctly employed are as follows:

\begin{tabular}{|c|c|c|}
\hline \multicolumn{2}{|c|}{ Young's modulus: average over column volume } & $\mathrm{E}_{\mathrm{col}}=60 \mathrm{MPa}$ \\
\hline Inter-granular & pea gravel & $\varphi_{\mathrm{c}}^{\prime}=38$ degrees \\
\hline internal angle & crushed stone gravel & $\varphi_{\mathrm{c}}^{\prime}=40$ degrees \\
\hline \multicolumn{2}{|l|}{ Poisson's ratio } & $v_{\text {col }}=1 / 3$ \\
\hline \multicolumn{2}{|c|}{ Unit weight of saturated material in place } & $\gamma_{\text {col }}=21 \mathrm{kN} / \mathrm{m}^{3}$ \\
\hline
\end{tabular}

Comment 1: Higher or lower values are possible, but must be explained by appropriate tests.

\section{4}

\section{Maximum allowable stress for stone columns}

(1) To calculate the maximum allowable stress, first determine the vertical stress-rupture point $q_{r}$ for an isolated column based on the characteristics of the 
column and of the soil after treatment, and according to the possible modes of failure illustrated below (Fig. 4 a, b and c; see Soyez; 1985):

- Bulging failure (a criterion often used to determine size)

- General shear failure (failure is rare, occurring when columns are short).

- Punching effect shear failure ("floating columns").

a)

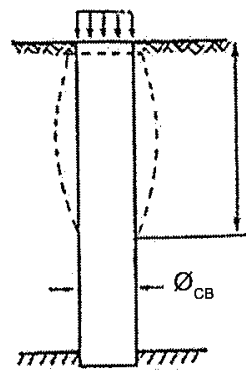

b)

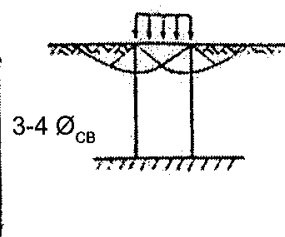

a) column bulging failure

b) general shear failure

c) punching effect failure (floating column)

c)

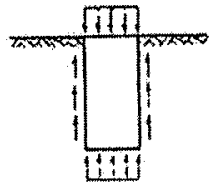

\section{4xis:}

\section{Bulging failure}

(1) By analogy with the triaxial conditions, the effective lateral expansion failure stress $\mathrm{q}_{\mathrm{re}}$ is given according to the depth and radial stress $\sigma_{\mathrm{r}}$ by:

- $\mathrm{q}_{\mathrm{re}}=\sigma_{\mathrm{r}} \cdot \tan ^{2}\left(\pi / 4+\varphi_{\mathrm{c}}^{\prime} / 2\right)$ Greenwood (1970)

(2) The radial stress value results from the geotechnical context and is estimated based on laboratory tests (triaxial tests) or in situ tests (pressuremeter, vane tests and cone penetration tests) as part of the project's geotechnical study.

Comment 1: For example, for the pressuremeter, the radial stress is estimated as follows for each soil layer:

- $\sigma_{\mathrm{r}} \# p_{l e}{ }^{*}$

If in addition, $\varphi_{c}^{\prime}$ is around 38 degrees, then:

- $q_{r e} \# 4 . p_{l e}{ }^{*}$

Where $p_{l e}$ "is the equivalent net maximum pressure calculated according to the following formula:

- $p_{l}{ }^{*}=\min /\left(p_{l e}{ }^{*}[z]\right)$ over the length of the column at each layer

- with $p_{1 e}{ }^{*}[z]=$ geometric average of $p_{1}^{*}$ values over a length of $2 \oslash_{S C}$ centered on $z$, but limited to 1.5 times the lowest $p_{1}^{*}$ value for a length of $2 \varnothing_{S C}$.

Comment 2: For example, for CPTS, the radial stress is estimated as follows for each soil layer:

- $\sigma_{r} \# q_{c e} / 3$

If in addition, $\varphi_{C}^{\prime}$ is approx. 38 degrees, then:

- $q_{\text {re }} \# 4 / 3 \cdot q_{c e}$

Where $q_{c e}$ is the equivalent cone resistance calculated according to the following formula:

- $q_{c e}=\min \left(q_{c e}[z]\right)$ over the length of the column at each layer

- with $q_{c e}[z]$ calculated according to the following formula:

$$
q_{c e}[z]=\frac{1}{2 D} \int_{z-D}^{z+D} q_{c}(z) d z \text { where } D=\varnothing_{S C}
$$

- corresponding to an average over a length of $2 \varnothing_{S C}$ centered on $\mathrm{z}$.

\section{5}

\section{General shear failure}

(1) General shear failure can be studied when the characteristics of the column closely resemble those of the soil. This occurs only very rarely and the corresponding calculation does not appear in this document (see Soyez, 1985).

\section{3.}

\section{Punching effect shear failure}

(1) The vertical shear within the column is most intense at the top and decreases as it moves down (see Soyez, 1985).

(2) In a homogenous, cohesive undrained environment $C_{u}$ the vertical shear failure compared to the punch effect shear failure at the base of the column is $9 C_{u}$. Therefore, the maximum stress at the head $q_{r p}$ is determined according to the following formula:

- $q_{r p}=9 \cdot C_{u}+L_{c} \cdot\left(2 \cdot C_{u} / R_{c}-g_{c}\right)$ where:

- $\gamma_{c}$ : column unit weight of column material,

- $L_{\mathrm{c}}$ : column length,

- $\mathrm{R}_{\mathrm{c}}$ : average radius of the column.

Comment 1: Minimum value that balances out the ground resistance:

- ULS load: $L_{c} \geq R_{c}\left[\left(\gamma_{U L S}, \sigma_{\text {oULS }} / C_{u}\right)-9\right] / 2$

- SLS load: $L_{c} \geq R_{c}\left[\left(\gamma_{S L S}, \sigma_{\text {OSLS }} / C_{u}\right)-9\right] / 2$

- $\sigma_{0}$ is the column head stress

- with $\gamma_{U L S}=1.5$ and $\gamma_{S L S}=2$

(3) For multilayer soil, the formula becomes:

- $\mathrm{q}_{\mathrm{rp}}=9 \cdot \mathrm{C}_{\mathrm{up}}+\mathrm{L}_{\mathrm{c}}\left(2 \cdot \mathrm{C}_{\mathrm{um}} / \mathrm{R}_{\mathrm{c}}-\gamma_{\mathrm{c}}\right)$ where:

- $\mathrm{C}_{\text {up }}$ is the soil cohesion at the column base,

- $\mathrm{C}_{\mathrm{um}}$ is the average cohesion along the length of the column.

(4) The cohesion values $\left(\mathrm{C}_{u^{\prime}} \mathrm{C}_{\mathrm{up}}\right.$ and $\left.\mathrm{C}_{\mathrm{um}}\right)$ result from the geotechnical context and are estimated based on laboratory tests (triaxial tests) or in situ tests (pressuremeter, vane tests and cone penetration tests) as part of the project's geotechnical study.

Comment 1: For example, for the pressuremeter the following can be used:

- $C_{u} \# p_{l} * / 5.5$ when $p_{1}^{*}<.3 \mathrm{MPa}, C_{u}$ in $M P a$

- $C_{u} \# p_{1}^{*} / 10+.025$ when $p_{1}^{*} \geq 0.3 \mathrm{MPa}, C_{u}$ in $\mathrm{MPa}$

Comment 2: For example, for CPTS the following can be used:

- $\mathrm{C}_{\mathrm{u}} \#\left(\mathrm{q}_{\mathrm{c}}-\mathrm{p}_{\mathrm{o}}\right) / 15$ where $\mathrm{p}_{\mathrm{o}}$ is the total vertical stress for the level in question

Comment 3: Under the footings, the columns are always considered non-floating according to the following criterion.

A non-floating column is defined as one that stops within a horizon characterized by $C_{u p}$ greater than or equal to $150 \mathrm{kPa}$ (or approximately $p_{1}^{*} \geq .8 \mathrm{MPa}$ or $q_{\mathrm{c}} \geq 2.5 \mathrm{MPa}$ ) or such that $9 . C_{u p}>q_{r}$ 
Comment 4: In all cases, it is necessary to calculate and take into account the settlement of the soil underneath the columns.

\section{mis}

\section{Stresses within the columns}

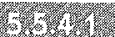

Failure stress

(1) Vertical failure stress $q_{r}$ within the column is equal to:

- $\mathrm{q}_{\mathrm{r}}=\min \left(\mathrm{q}_{\mathrm{re}} ; \mathrm{q}_{\mathrm{rp}} ; 1.6 \mathrm{MPa}\right)$

\section{2}

\section{SLS stress}

(1) At the service limit state (SLS), the allowable vertical stress $q_{\text {aSLS }}$ within the column is obtained by applying a safety factor of 2 to the vertical failure stress $\mathrm{q}_{\mathrm{r}}$ :

- $\mathrm{q}_{\mathrm{aSLS}}=\mathrm{q}_{\mathrm{r}} / 2=\min \left(\mathrm{q}_{\mathrm{re}} / 2 ; \mathrm{q}_{\mathrm{rp}} / 2 ; 0.8 \mathrm{MPa}\right)$

\section{0}

\section{ULS stress}

(1) The maximum stress for calculation $q_{a u s s}$ within the column is obtained by applying a safety factor of 1.5 on the vertical failure stress $q_{r}$ :

- $\mathrm{q}_{\mathrm{aULS}}=\mathrm{q}_{\mathrm{r}} / 1.5=\min \left(\mathrm{q}_{\mathrm{re}} / 1.5 ; \mathrm{q}_{\mathrm{rp}} / 1.5 ; 1.06 \mathrm{MPa}\right)$

Comment 1: This means applying a coefficient of 1.33 to the allowable stress at the ULS:

- $q_{a U L S}=1.33 \cdot q_{a S L S}$

\section{5}

\section{Evaluating stress and settlement at the service limit state (SLS)}

(1) The methods described below ( $\$ 5.5 .1$ and 5.5.2) are usually only valid if:

- The additional load on the soil between the columns (calculated according to the aforementioned methods) remains inferior to the allowable stress for the untreated soil. layer.

- The column bases rest on a more compact ground

Comment 1: A layer is considered more compact when it is characterized by $C_{u p}$ greater than or equal to $150 \mathrm{kPa}$ (approximately $p_{1}^{*} \geq 0.8 \mathrm{MPa}$ or $q_{c} \geq 2.5 \mathrm{MPa}$ ) or such that 9. $C_{u p}>q_{r}$.

(2) They are based on the soil elasticity hypotheses and on the conservation of flat, horizontal sections and depend on the stiffness of each element (soil and columns)

Comment 1: As part of pressuremeter and cone penetration test methods, to remain within the elastic range under the foundation element (raft foundation, concrete slab, footing, etc.) it must be verified that in the SLS:

- $q_{\text {sol }}<k_{p} \cdot p / 2+q_{0}^{\prime}$ for pressuremeter tests

- $q_{\text {sol }}<k_{c} \cdot q_{c} / 2+q_{0}^{\prime}$ for CPT where $q_{\text {sol }}$ is the maximum stress transferred to the soil between the columns.

(3) Other methods are also available. It is necessary to use the orders of magnitude obtained under special conditions as follows.

Comment 1: These calculation methods should make it possible to verify the bearing capacity and settlement criteria described in $\$ 5.5 .1,5.5 .2$ and 5.6.

\section{6.}

\section{Homogenization method for concrete slabs} and raft foundations subject to uniform, infinite loads

(1) After constructing the columns, the settlement for each layer $i$ at the center of the building is expressed as follows:

$$
\left.w_{i}=\frac{h_{i} \cdot \sigma_{t}}{a_{i} \cdot E_{c o l}+\left\{\left(1-a_{i}\right) E_{s i}\left(1-v_{s i}\right) /\left(1-v_{s i}-2 v_{s i}^{2}\right)\right.}\right\}
$$

and the value of the stress within the column at the layer $i\left(\mathrm{~S}_{\mathrm{ci}}\right)$ can be expressed as:

$$
\left.\sigma_{\mathrm{ci}}=\frac{\mathrm{E}_{\mathrm{col}} \cdot \sigma_{\mathrm{t}}}{\mathrm{a}_{\mathrm{i}} \cdot \mathrm{E}_{\mathrm{col}}+\left\{\left(1-\mathrm{a}_{\mathrm{i}}\right) \mathrm{E}_{\mathrm{si}}\left(1-\mathrm{v}_{\mathrm{si}}\right) /\left(1-v_{\mathrm{si}}-2 \mathrm{v}_{\mathrm{si}}{ }^{2}\right)\right.}\right\}
$$

where:

- $\mathrm{a}_{\mathrm{i}}$ : the replacement ratio for layer $\mathrm{i}$

- $\mathrm{E}_{\mathrm{col}}$ : Young's modulus for the column

- $\mathrm{E}_{\mathrm{si}}$ : Young's modulus for layer $\mathrm{i}$

- $v_{\mathrm{si}}$ : Poisson's ratio for layer i

- $\sigma_{\mathrm{t}}$ : average vertical stress exerted by the building

- $h_{\mathrm{i}}$ : thickness of layer $\mathrm{i}$

Comment 1: If there are results from laboratory oedometer tests (oedometric modulus for soil layer i: $E_{\text {soli }}$ ), the above formulas become:

$$
w_{i}=\frac{h_{i} \cdot \sigma_{t}}{a_{i} \cdot E_{\text {col }}+\left\{\left(1-a_{i}\right) E_{\text {soli }}\right\}}
$$

and the stress within the column at the layer $i\left(S_{c i}\right)$ can be expressed as:

$$
\sigma_{\mathrm{ci}}=\frac{\mathrm{E}_{\mathrm{col}} \cdot \sigma_{\mathrm{t}}}{\mathrm{a}_{\mathrm{i}} \cdot \mathrm{E}_{\mathrm{col}}+\left\{\left(1-\mathrm{a}_{\mathrm{i}}\right) \mathrm{E}_{\mathrm{soli}}\right\}}
$$

Comment 2: If there are results from pressuremeter tests (modulus $E_{M}$, coefficient a), in keeping with International Society for Soil Mechanics and Geotechnical Engineering recommendations, the ratio $E_{M} / \alpha$ is compared to the oedometric modulus.

In the traditional hypothesis with a Poisson's ratio of $1: 3$, the Young's modulus for soil $E_{s}$ is then equal to $2 / 3$ of the oedometric modulus.

The above formulas become:

$$
\mathrm{w}_{\mathrm{i}}=\frac{\mathrm{h}_{\mathrm{i}} \cdot \sigma_{\mathrm{t}}}{\mathrm{a}_{\mathrm{i}} \cdot \mathrm{E}_{\mathrm{col}}+\left\{\left(1-\mathrm{a}_{\mathrm{i}}\right) \mathrm{E}_{\mathrm{Mi}} / \alpha_{\mathrm{i}}\right\}}
$$


and the stress within the column at the layer $i\left(S_{c i}\right)$ can be expressed by:

$$
\sigma_{\mathrm{ci}}=\frac{\mathrm{E}_{\mathrm{col}} \cdot \sigma_{\mathrm{t}}}{\mathrm{a}_{\mathrm{i}} \cdot \mathrm{E}_{\mathrm{col}}+\left\{\left(1-\mathrm{a}_{\mathrm{j}}\right) \mathrm{E}_{\mathrm{Mi}} / \alpha_{\mathrm{i}}\right\}}
$$

Comment 3: If there are results from electric cone penetration tests ( $C P T$ ), the following correlations can be made for the most common and normally consolidated soil types:

- $E_{\text {sol }}=\alpha_{c} \cdot q_{c}$ avec $\alpha_{c}$ common values appear in the table below

- with the oedometric modulus $E_{\text {sol }}$ for the soil

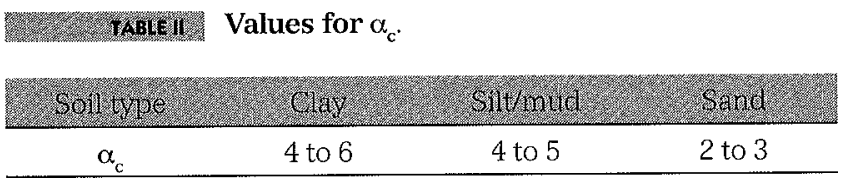

Note: For other soil types and/or over-consolidated soils, other correlations can be made.

The above formulas become:

$$
w_{i}=\frac{h_{i} \cdot \sigma_{t}}{a_{i} \cdot E_{c o l}+\left\{\left(1-a_{i}\right) \alpha_{c} \cdot q_{c i}\right\}}
$$

and the stress within the column at the layer i $S_{c i}$ lcan be expressed by:

$$
\sigma_{\mathrm{ci}}=\frac{\mathrm{E}_{\mathrm{col}} \cdot \sigma_{\mathrm{t}}}{\mathrm{a}_{\mathrm{i}} \cdot \mathrm{E}_{\mathrm{col}}+\left\{\left(1-\mathrm{a}_{\mathrm{i}}\right) \alpha_{\mathrm{c}} \cdot \mathrm{q}_{\mathrm{ci}}\right\}}
$$

Comment 4: Since pressuremeter and CPT correlations can be difficult to make for certain types of soil (saturated soft clay, unsaturated soil, etc.), oedometric moduli measured in a laboratory may be preferable.

(4) The stresses should remain below the maximum allowable values specified in 5.4.4.2

- $\sigma_{c i}<q_{a i}$

The total settlement $\left(\Sigma w_{i}\right.$, increased if necessary by the settlement of layers under the bases of the columns) should remain below the values set by the operating conditions.

Comment 1: If the load varies from one area to another and/or if the stratigraphy is not uniform, it is necessary to also check if the differential settlement values are acceptable.

Comment 2: If the column bases do not rest on a more compact layer, a specific explanation is offered.

\section{6.}

\section{Columns under footings with vertical and centered load bearing}

\section{Whats.}

\section{SLS loads}

(1) The steps for calculation are the following for a given footing (whose surface $S_{s}=B$. L) supported on $n$ columns (with area $\mathrm{S}_{\text {col }}$ ), bearing surface load $\mathrm{q}_{\mathrm{SLS}}$.
Comment 1: In all cases, it is necessary to calculate and take into account the settlement beneath the columns.

\section{2}

\section{Bearing capacity in the Ultimate Limit State (ULS)}

(1) For a given footing (with area $S_{s}=B$. L) supported on $n$ columns (with area $S_{\text {col }}$ ), with a surface overload $\mathrm{q}_{\mathrm{UL} \mathrm{S}^{\prime}}$ the following must be verified:

$\left\{\mathrm{n} \cdot \mathrm{S}_{\text {col }} \cdot \mathrm{q}_{\mathrm{aULS}}+\left(\mathrm{S}_{\mathrm{s}}-\mathrm{n} \cdot \mathrm{S}_{\mathrm{col}}\right) \cdot \mathrm{q}_{\mathrm{u}}^{\prime} / 2\right\}>\mathrm{q}_{\mathrm{ULS}} \mathrm{S}_{\mathrm{s}}$

Comment 1: If there is a need for deformation at the ULS, the method described for SLS can be used as an initial approach.

\section{6}

\section{Stresses other than vertical centered loads}

(1) Given a footing with dimensions B. L subject to vertical loads and overturning moments, the elements at the center are the vertical load $Q(Q=q . B . L)$ and bending moments $M_{x}$ and $M_{y}$; $L$ is parallel to the $x$ axis.

(2) Assuming that there are columns along more than one parallel axis (at the SLS and ULS):

- Along the $x$ axis from $M_{x} / Q>B / 6$

- Along the $y$ axis from $\mathrm{M}_{\mathrm{y}} / \mathrm{Q}>\mathrm{L} / 6$.

(3) The methods described in $\S 5.8$ deal with the question in different ways. Below is a simplified method.

\section{3.}

\section{Simplified method} to:

(1) The value of $M_{x}$ is increased by a factor $\psi_{x}$ equal

- 1.25 if there are columns along several axes parallel to the $x$ axis

- and 1.5 if the opposite is true (all columns are aligned along the $\mathrm{x}$ axis). to:

(2) The value of $M_{y}$ is increased by a factor $\psi_{x}$ equal

- 1.25 if there are columns along several axes parallel to the $y$ axis

- and 1.5 if the opposite is true (all columns are aligned along the $y$ axis).

(3) The eccentricity values $e_{y}=\psi_{x} \cdot M_{x} / Q$ and $e_{x}=\psi_{y}$ . M/Q should verify:

$e_{x}<d_{x}$ and $e_{y}<d_{y}$.

(4) Therefore, we can refer to an equivalent rectangular layout (Meyerhof) $q^{\prime}$ :

$\mathrm{q}^{\prime}=\mathrm{q} \cdot \mathrm{B} \cdot \mathrm{L} / \mathrm{S}_{\mathrm{r}}$ with $S_{r}=\left(B-2 \cdot e_{y}\right) \cdot\left(L-2 . e_{x}\right)$

(5) It is then possible to apply the simplified methods described in $\S 5$ 5.2.1 to the compressed part of the footing.

(6) For a column to be taken into account in the calculation, it is necessary to verify that it is located in the part of the soil that is entirely compressed. The increase in $y$ of 1.25 and/or 1.5 makes it possible to avoid this verification by determining the dimensions in advance. 


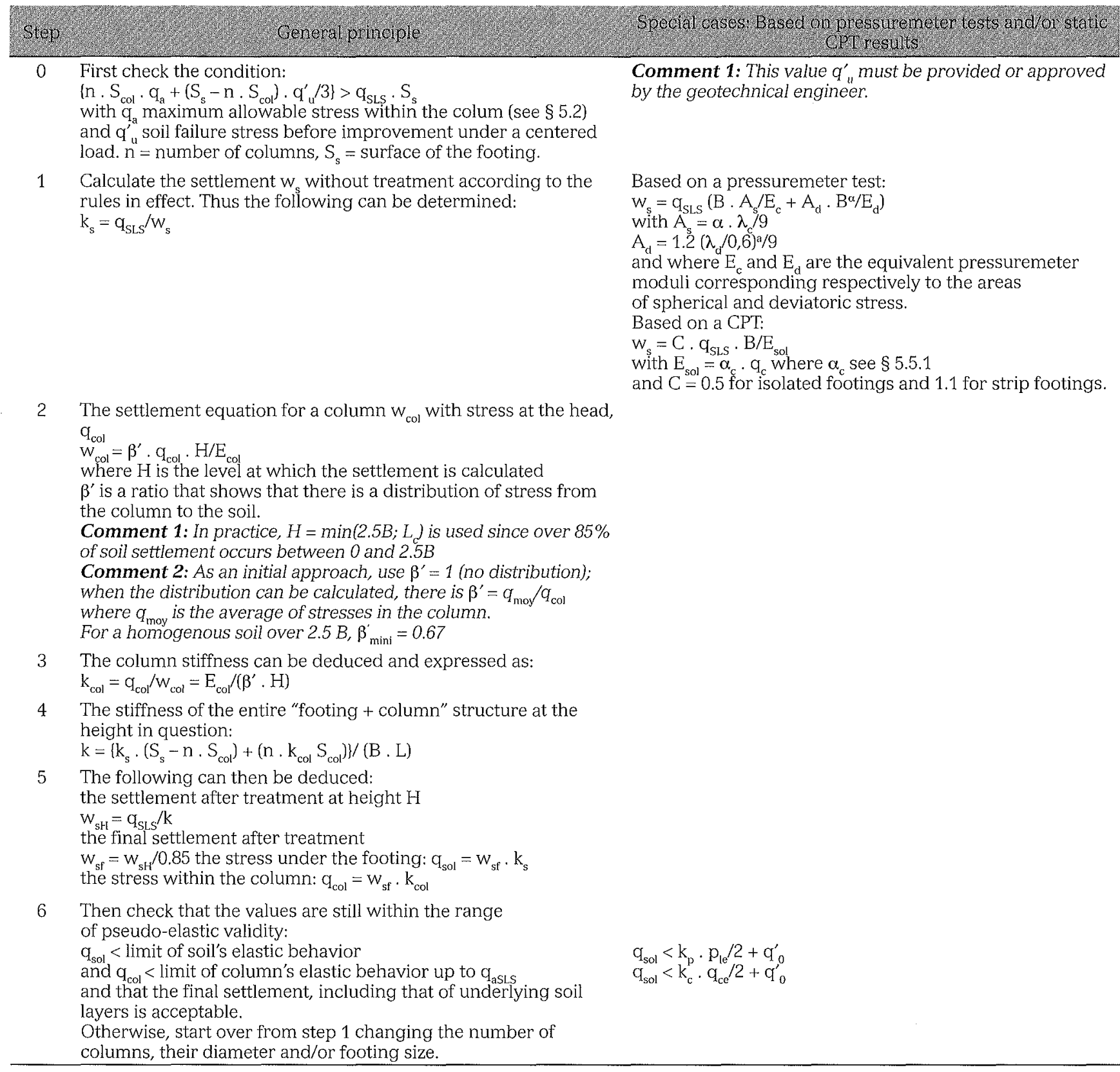

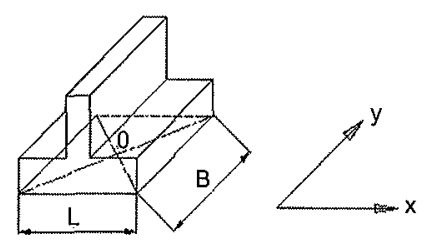

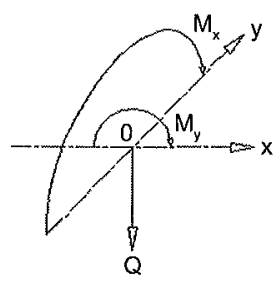

FiG 5 . Orientation of the bending moments.

(7) Check that in the rare SLS, $75 \%$ of the surface of the footing remains compressed, that in the quasipermanent SLS, $100 \%$ of the surface remains compressed, and then in the ULS, about half of the number of columns remains under the entirely compressed surface $S_{r}$.

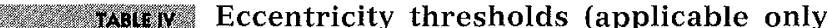
when: $M x=0$ and $M y \neq 0$ or $M x \neq 0$ and $\mathrm{My}=\mathbf{0}$ ).

\begin{tabular}{|c|c|c|}
\hline quasi-permanent SLS & $<\mathrm{L} / 6$ & $<\mathrm{B} / 6$ \\
\hline rare SLS & $<\mathrm{L} / 4$ & $<\mathrm{B} / 4$ \\
\hline ULS & $<\mathrm{L} / 2.2$ & $<\mathrm{B} / 2.2$ \\
\hline
\end{tabular}




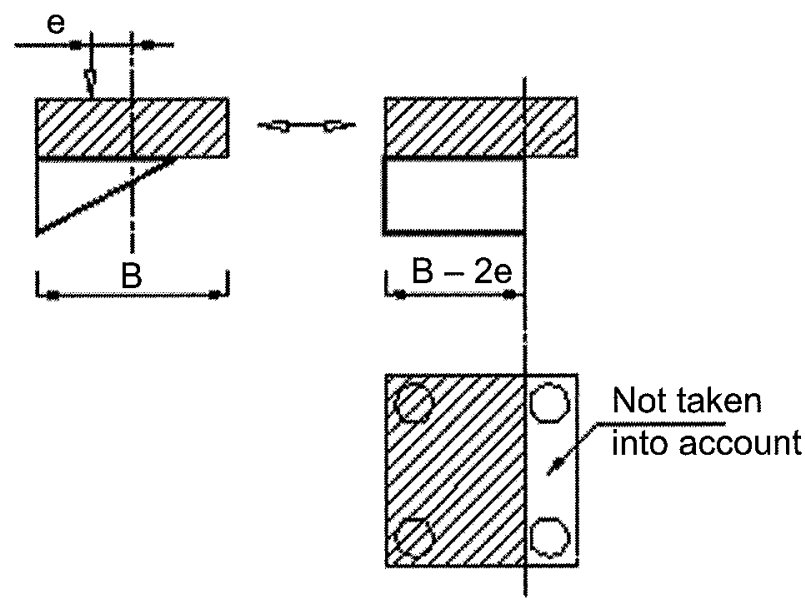

Taking into account columns in compressed areas.

tion of the distribution of the stress applied under the footing remains within the valid range of settlement formulas.

$q_{\text {réf }}^{\prime}=\left(3 \cdot q_{\max }+q_{\text {min }}\right) / 4$, ou $q_{\text {réf }}^{\prime}=Q /\left(B-2 \cdot e_{y}\right)\left(L-2 \cdot e_{x}\right)$
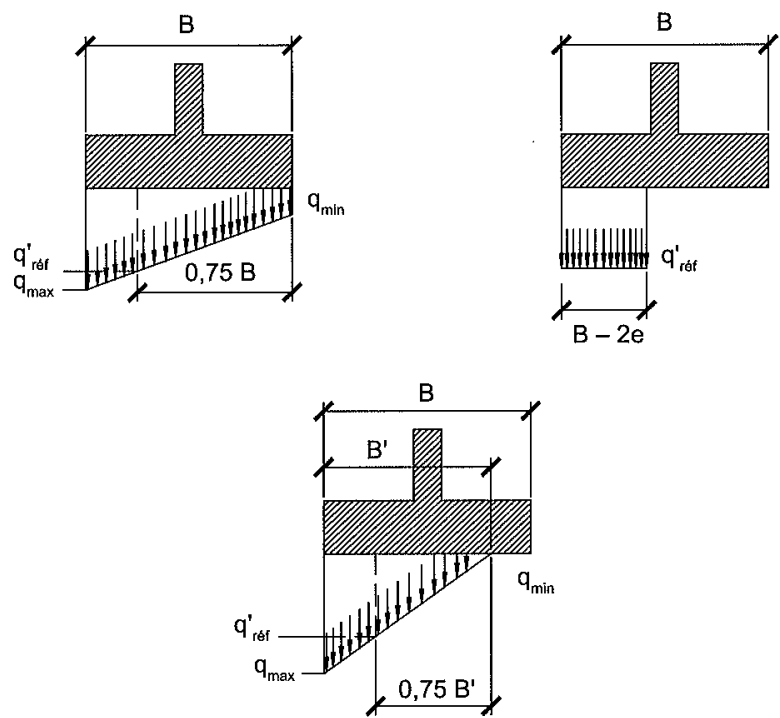

116. 1 Calculation of $\mathrm{q}^{\prime}{ }_{\text {ref }}$

Comment 1: As part of pressuremeter and CPT methods, the following must be verified:

- The stresses in the soil must remain within allowable limits: $\S 5.5 .2 .1)$

- $q_{\text {réf }}^{\prime}<k_{p} \cdot p_{l e} / 2+q_{o}^{\prime}$

- $q_{r e f}^{\prime}<k_{c}, q_{c e} / 2+q_{o}^{\prime}$ (see step 6 on the table in

- The stresses within the columns must remain within allowable limits:

- $q_{\text {col }}<q_{\text {aSLS }}$ in the SLS

- $q_{\text {col }}<q_{\text {aULS }}$ in the ULS

- The overall bearing capacity is verified as follows

- $q^{\prime}=q . B . L /\left[\left(B-2 . e_{y}\right)\left(L-2 . e_{x}\right)\right]$
- $\mathrm{n}_{\mathrm{r}} \cdot \mathrm{S}_{\mathrm{col}} \cdot \mathrm{q}_{\mathrm{aSSS}}+\left(\mathrm{S}_{\mathrm{r}}-\mathrm{n}_{\mathrm{r}} \cdot \mathrm{S}_{\mathrm{col}}\right) \cdot \mathrm{q}_{\mathrm{u}}^{\prime} / 3>\mathrm{q}_{\mathrm{SLS}}^{\prime} \cdot \mathrm{S}_{\mathrm{r}}$ with $n_{r}$ number of columns under the compresses surface $S_{r}$ in the SLS

- $n_{\mathrm{r},} \mathrm{S}_{\mathrm{col}} \cdot \mathrm{q}_{\mathrm{aULS}}+\left(\mathrm{S}_{\mathrm{r}}-\mathrm{n}_{\mathrm{r}} \cdot \mathrm{S}_{\text {col }}\right) \cdot \mathrm{q}_{\mathrm{u}}^{\prime} / 2>\mathrm{q}_{\text {ULS }}^{\prime} \mathrm{S}_{\mathrm{r}}$ with $n_{r}$ number of columns under the compressed surface $S_{r}$ in the ULS

- with $\mathrm{q}_{\text {ass }}$ : maximum allowable stress in the column at the SLS

- with $q_{\text {as: }}$ maximum allowable stress in the column at the ULS

- $\mathrm{q}_{\mathrm{u}}^{\prime}$ : soil failure stress before improvement under a centered load

- Check that in the rare SLS, $75 \%$ of the surface of the footing remains compressed, that in the quasipermanent SLS, $100 \%$ of the surface remains compressed, and then in the ULS, about half of the number of columns remains under the entirely compressed surface $\mathrm{S}_{\mathrm{r}}$.

\section{7}

\section{Special provisions for embankments (uniform load)}

(1) The calculations for stone columns underneath embankments are carried out as for columns under raft foundations and concrete slabs subject to uniform loads.

(2) These structures may require stability verification in terms of sliding and soil creep.

(3) In this context, the following need to be distinguished:

- The initial model corresponding to the beginning of the load bearing without any load transfer

- The gradual load transfer model (drainage phase)

- The final model after the full load transfer (end of drainage).

(4) Regarding this issue, Priebe (1978) suggests solutions for homogenization that, according to Mitchel (1981), can be applied over the long-term (final load transfer model) making it possible to obtain an equivalent, simplified model.

(5) This simple approach does not allow for consideration of the load transfer mechanism and can underestimate the safety factor when the incorporation rate increases.

\section{8}

\section{Other evaluation methods}

(1) In all cases, step 0 described in $\S 5.5 .2 .1$ must be applied.

\section{6.}

\section{Numerical finite element approach}

(1) The finite element method consists of defining a geometric model (soil + columns) in numerical subsets based on conditions of displacement and stress in order to build an overall rigidity matrix.

(2) Then for each given law of behavior and for each load situation studied, the displacement, deformation, 
and stress are calculated precisely according to the defined model.

(3) This method offers the advantage of including all of the parameters of the chosen model (displacement, deformation, stress, iso-values for parameters and areas of prior plastification).

(4) Nevertheless, this approach requires special attention to the modelization of the columns and limit conditions. The results depend a great deal on the rheological model and its geo-mechanical parameters (in particular, the Young's modulus, Poisson's ratio, $C_{c^{\prime}} C_{s^{\prime}}$ etc.) that must be validated by the geotechnical engineer

\section{5.}

\section{Homogenization methods}

(1) Homogenization methods offer the advantage of simplifying the "combined soil + columns" context to obtain a basic model where the treated environment is reduced to an equivalent homogenous environment.

(2) The simplified homogenization technique was first used by Priebe (1978) for stability calculations for embankments on top of soft soil reinforced with stone columns.

Comment 1: The method described in $\S 5.5 .1$ is a homogenization method.

\section{9}

\section{Possible effects on structural calculations}

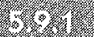

\section{Concrete slabs on a load transfer platform}

(1) Several methods for calculating stresses on the structures are possible.

Comment 1: For concrete slabs, the "soil onsite + column" can also be assimilated with a homogenous soil (for which the modulus should be defined) in the following cases:

- Distributed load less than or equal to $30 \mathrm{kPa}+$ load transfer platform of a thickness greater than or equal to $40 \mathrm{~cm}$ with a minimum $\mathrm{EV}_{2}$ of $50 \mathrm{MPa}$ and a maximum grid of $9 \mathrm{~m}^{2}$.

- Distributed load between $30 \mathrm{kPa}$ to $50 \mathrm{kPa}+$ load transfer platform of a thickness greater than or equal to $60 \mathrm{~cm}$ with a minimum $\mathrm{EV}_{2}$ of $80 \mathrm{MPa}$ and a maximum grid of $7.5 \mathrm{~m}^{2}$.

\section{3.}

Simplified method based

on the subgrade reaction modulus

(1) The model provides a distribution of surface springs equivalent to the "load transfer platform + reinforced soil" combination. In practice, this distribution can be described with two types of values: the values applicable vertically and around the column set by a slope of $2 \mathrm{~V} / 1 \mathrm{H}$ from the top of the column, and those applicable to the additional surface.

(2) The structure is assimilated with a beam or plate on elastic supports for which the values for each area are subtracted from the preceding calculation.
(3) For concrete slabs, the expansion of the model should take into account the position of the joints and limiting conditions. The verifications must cover the entire vertical load in both distributed and special situations.

(4) Determining the dimensions of the structure should be based on a model that can take the soilstructure interaction into account

\section{1 152}

Other methods

(1) Among other methods, the following can be cited

- The "additional moments" envelope method involves defining corrective terms associated with the presence of the columns. These are added as an envelope to the concrete slab stresses (bending moment) calculated according to Appendix $C$ of standard NF P 11 213-1 for the central part, panel edges and angles on equivalent homogenized soil. There are two of these corrective terms:

- One that represents the influence of the columns on a continuous concrete slab.

- Another that represents the interaction between the columns and the joints.

- Calculations based on the finite element method.

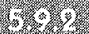

\section{Footing or raft foundation with or without a load transfer platform}

(1) To calculate the reinforcement for strip footings or a raft foundation, the difference in stiffness between the soil and the columns and the different load situations are taken into account.

Comment 1: The minimum reinforcement specified in French standards for isolated footings is usually enough if the construction provisions in Appendix I are followed.

Comment 2: It is important to be especially careful with structures for which no minimal reinforcement is specified in the standards.

Comment 3: For footings with a load transfer platform, if the cones of influence meet, the "soil onsite + column" can be assimilated with a homogenous soil which can lead to using a traditional reinforced concrete calculation.

\section{6}

\section{Quality control and acceptance}

\section{1 \\ Quality control during installation}

\section{(2).}

\section{Calibration tests}

(1) At the start of any stone column construction project, the contracting company must carry out cali- 
bration tests to validate the choice of material and verify the compliance of soil reactions with expected behavior (depths attained, consumption, possible swelling, effects from vibrations, etc.).

(2) If the preliminary soil study shows remarkable heterogeneity in the depths, nature or characteristics of the layers to be treated, calibrations should be carried out for each of the different areas in question.

(3) These tests are preferably carried out in the vicinity of the soil sampling or borings for the geographical study.

Comment 1: The calibration tests are specific information tests.

\section{5.}

\section{Informational tests}

(1) The stone column installation parameters are provided for one column per 50 (with a minimum of 3 per structure): depth, energy consumed and overall volume of incorporated material.

Comment 1: These tests can be in the form of electronic data as long as all of the parameters are entered.

\subsection{1.}

\section{Attachments}

(1) This reference document specifies the characteristics for each column: date of installation, depth, energy consumed, incorporated volume, etc. used.

(2) It also specifies the material and process to be

Comment 1: These attachments can be in the form of electronic data for all columns with the depth, energy consumed and volume incorporated.

\section{9}

\section{Acceptance tests}

(1) Unless otherwise specified by the contractor, these tests are to be carried out by the project construction company and include (details in the table below):

- Checking the column diameter.

- Checking continuity in case of a data entry error.

- Compaction verification.

- Load test.
Comment 1: These tests must be carried out by an expert approved by the contractor.

(2) The results are entered together in the project's quality control report.

(3) In addition, the installation tolerance (see $§ 4.9$ ) is verified for one column per 80 for concrete slabs and raft foundations and by random sampling for all columns under footings.

Comment 1: The columns installed outside the tolerances are identified on a blueprint for verification.

\section{6)}

\section{Diameter verification}

(1) Columns outside the building footprint can be side-stripped at different layers deep enough for diameter verification.

(2) For feasibility reasons, this excavation is usually done from the top of the column to a minimum depth of 1 meter beneath the platform.

\section{2}

\section{Checking continuity}

(1) Static cone penetration tests (standard NF P 94.113) are suited to this verification, though dynamic CPTs (NF P 94.114) can also be carried out.

\section{6.}

\section{Compaction verification}

(1) This verification is carried out with a static CPT (standard NF P 94.113).

(2) This test must be done down to $1 \mathrm{~m}$ below the tip of the column except in the case of refusal on the underlying layer.

(3) To be consistent with the characteristics described in $\$ 5.3$, the minimal characteristic for all points along the column axis from 1 meter below the column base must be equal to:

$\mathrm{q}_{\mathrm{cm}}=10 \mathrm{MPa}$

Comment 1: If the values are lower, specific justifications must be provided.

Comment 2: A reminder of the definition of the leveled tip resistance $\left(q_{c m}\right)$

\begin{tabular}{|c|c|c|c|c|}
\hline & recorded & unrecorded & recorded & unrecorded \\
\hline Checking diameter & \multicolumn{4}{|c|}{1 per set of 50 columns up to 100 , beyond that at least 3} \\
\hline Checking continuity & $1 / 50$ & $1 / 20$ & $\begin{array}{l}\text { only if an anomaly } \\
\text { is detected }\end{array}$ & $1 / 50$ \\
\hline Compaction verification & \multicolumn{4}{|c|}{$\begin{array}{l}1 / 80 \text { under concrete slab or raft foundation }+1 / 20 \text { under ground mass } \\
\text { with a minimum of } 5\end{array}$} \\
\hline Load test* & \multicolumn{2}{|c|}{1 test up to $800 \mathrm{~m}$ and 1 per section beyond $800 \mathrm{~m}$} & \multicolumn{2}{|c|}{$\begin{array}{l}1 \text { test up to } 2,000 \mathrm{~m} \text { and } 400 \text { columns, and at least } \\
\text { one more beyond 2,000 } \mathrm{m}\end{array}$} \\
\hline
\end{tabular}

* For construction sites with less than $1,000 \mathrm{~m}$ of stone columns installed with the dry method ( $800 \mathrm{~m}$ by wet method), a load test may not be performed, but in this case the allowable stress must be reduced by a factor of 1.5 . 


$$
q_{c m}=\frac{l}{4 a} \int_{D-a}^{D+3 a} q_{c}(z) \cdot d z
$$

- $a$ is equal to $0.5 \mathrm{~m}$

- $D$ is the depth at which the characteristic is considered

- $q_{c}(z)$ is the measurement obtained and leveled to $1.3 q_{c m}$

Comment 3: Complications can arise to make these tests difficult to carry out:

- Blocking due to large pieces of column material

- Deviation of the drill pipe string, which can slip out of the column

If this occurs, the contractor must provide the recorded data for the column in question and suggest a new quality control plan.

Comment 4: The other usual in situ geotechnical tests, in particular pressuremeter tests (standard NF P 94.110) at every meter and type A dynamic CPTs (according to standard NF P 94.114) are more difficult to carry out in ballast-type materials.

- If the stability of the pressuremeter borehole walls cannot be guaranteed, the pressuremeter test can be carried out with a split spoon sampler (see NF P 94.110-1).

- To be consistent with the characteristics described in $§ 5.3$, the minimal characteristic for all points along the column axis starting from $1 \mathrm{~m}$ below the top of the column taking into account the most recent correlation must be respectively equal to:

- $\mathrm{p}_{1}=1.2 \mathrm{MPa}$

- $\mathrm{q}_{\mathrm{d}}=10 \mathrm{MPa}$

- If the values are lower, specific justifications must be provided.

\section{6}

\section{Load test}

(1) This load test is done at 1.5 times the SLS load for column $\mathrm{Q}_{\mathrm{N}}$ on one column at the site.

(2) The load test requires installing a footing on the top of the column, preferably leveled off under the load transfer platform. The surface of the footing should be less than 2.5 times the planned column section.

(3) This is a stress controlled test carried out with compression. It involves measuring how far the top of a column (with two or three values as a basis for comparison) settles under a vertical load.

(4) The load is applied gradually in six increments:

- $\mathrm{Q}_{\mathrm{N}} / 4, \mathrm{Q}_{\mathrm{N}} / 2,3 \mathrm{Q}_{\mathrm{N}} / 4, \mathrm{Q}_{\mathrm{N}}, 5 \mathrm{Q}_{\mathrm{N}} / 4$ and $3 \mathrm{Q}_{\mathrm{N}} / 2$.

(5) At each increment, the displacement is measured at the following intervals:

- $1,2,4,8,15,30,45$ and 60 minutes, or until the comparison values stabilize.

Comment 1: The deformation is considered to be "stable" when its variation does not exceed $.02 \mathrm{~mm}$ per minute.

Comment 2: The first increments can therefore be 30 minutes long.

(6) The column is unloaded in four increments held for 5 minutes.
(7) The test report includes:

- The loading/unloading plan with the measures for comparison by time and load amount.

- A chart showing settlement/time by increment.

- A diagram showing the settlement after each increment by load amount.

- A diagram showing the creep slope by load amount.

(8) The test is considered conclusive if these two criteria are met:

- The critical load ("creep") is not attained.

- The settlement at the end of the service load increment $\left(\mathrm{Q}_{\mathrm{N}}\right)$ is less than that estimated in the calculation report and is compatible with the tolerances set by the structure or building section.

\section{Glossary}

Column reference grid: The foundation area divided by the number of columns underneath it.

Replacement ratio: The ratio of the column section to the grid. It can vary according to the depth.

Vibro-compaction stone column: This type of column is formed by driving a pipe temporarily blocked at its base down to the desired depth. Granular material is then introduced through the pipe in small quantities and gradually compacted by pounding downwards. The pipe is then progressively pulled out so that the volume incorporated - always greater than the size of the pipe - matches the diameter in the design calculations. The diameter of the pipe depends on the soil and column characteristics. The driving weight is adapted to the pipe. The amount of energy is controlled by varying the drop height.

Dry method vibro-stone column: This type of column is formed by inserting a radial vibratory probe to the desired depth. Granular material is then reintroduced into the soil and repeatedly compacted with the probe. The energy required and retraction speed are adapted to the diameter and the degree of compaction specified by the design calculations. The drive system for the vibratory probe can be electric or hydraulic. Finally, filling is done from the bottom through a pipe attached either on the side or on top of the vibratory probe.

Wet method vibro-stone column: Same as for dry method stone columns, except that penetration is facilitated by water jetting (fresh or sea water).

Bottom-feed dry method vibro-stone column: Stone column where the granular material is injected from the bottom of the vibratory probe with a constant application of air pressure on the ballast, except when the supply pipe is being filled.

Deviation: Distance between the theoretical column installation location according to the design plans and the center of the column where it is actually installed. 


\section{Appendix i - Standard configurations for stone columns under foundation footings}

Comment 1: Illustrations are provided for columns with a diameter of $80 \mathrm{~cm}$. All dimensions are minimum measurements and are in centimeters.

\section{Comment 2:}

- Without a specific feasibility study, $d_{\min } \geq \operatorname{Max}\left(1.20 \mathrm{~m} ; 1.5 \Phi_{C B}\right)$ where $d_{\min }$ is the distance from axis to axis.

- Without any special explanation, the footing overhang in relation to the theoretical outer bare part of the column must be at least equal to the installation tolerance $(e=20 \mathrm{~cm})$.

\section{Isolated footings}

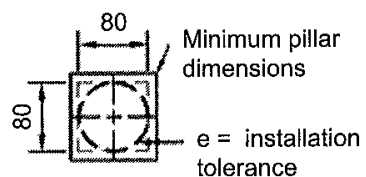
tolerance

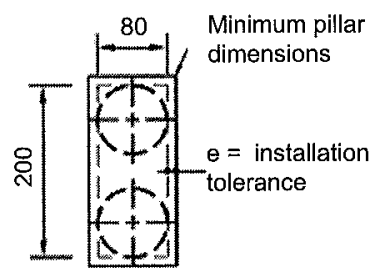

200 Minimum pillar
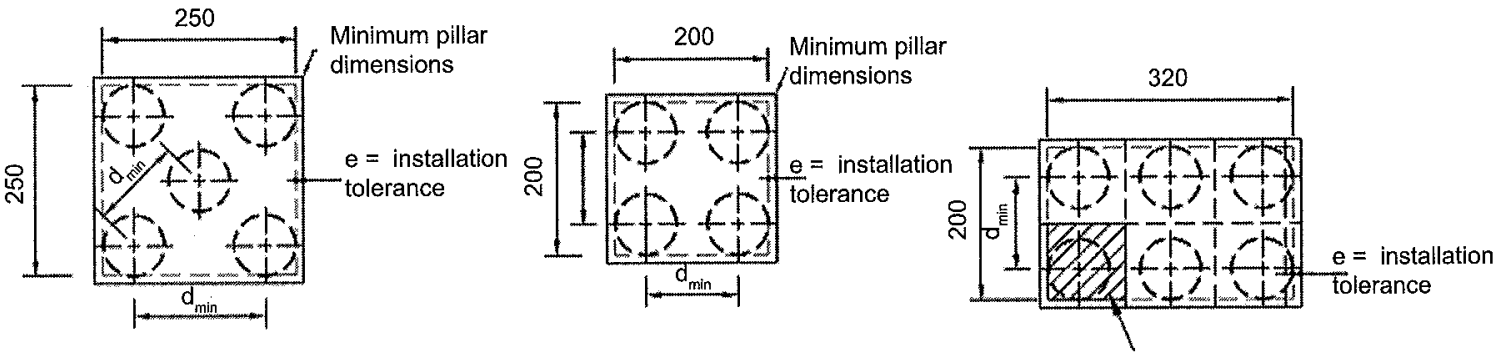

Reference grid

$144 \mathrm{~m}^{2}$ minimum

Strip footings
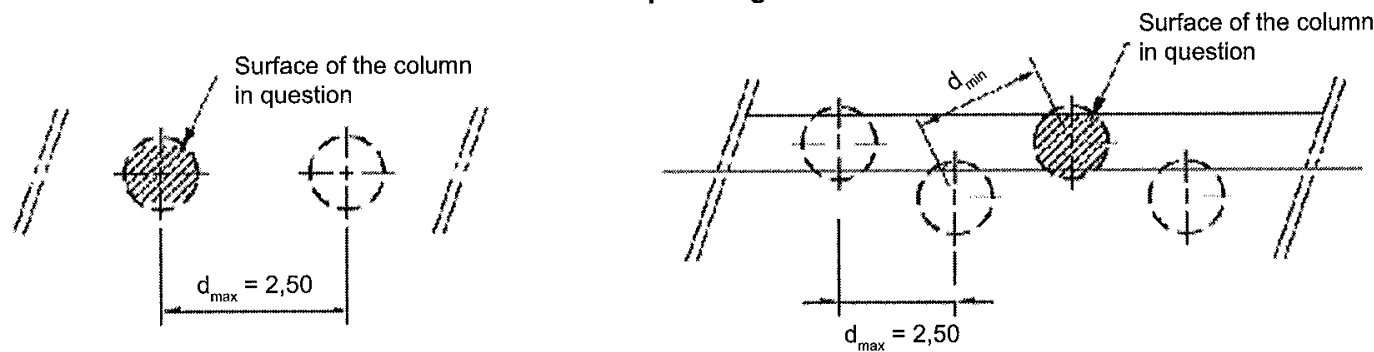

It is advisable to install the columns

in staggered rows order to avoid asymetry

in case of deviation.

Concrete slab raft foundation

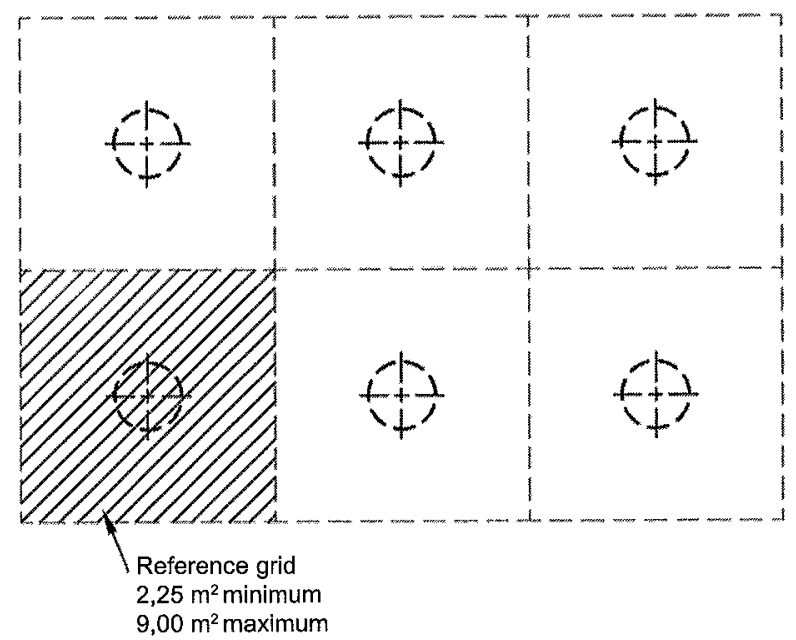

